\title{
Regulation of Defense Responses against Protozoan Infection by Interleukin-27 and Related Cytokines
}

\author{
Hiroki Yoshida, ${ }^{1}$ Yoshiyuki Miyazaki, ${ }^{1}$ Sen Wang, ${ }^{1}$ and Shinjiro Hamano ${ }^{2}$ \\ ${ }^{1}$ Department of Biomolecular Sciences, Faculty of Medicine, Saga University, Saga 849-8501, Japan \\ ${ }^{2}$ Department of Parasitology, Graduate School of Medical Sciences, Kyushu University, Fukuoka 812-8582, Japan
}

Received 26 November 2006; Revised 2 February 2007; Accepted 26 February 2007

Recommended by Ali Ouaissi

Cytokine-mediated immunity is crucial in the defense against pathogens. Recently, IL-23 and IL-27 were identified, which along with IL-12 belong to the IL-12 cytokine family. IL-27 is pivotal for the induction of helper T cell (Th) 1 responses while IL-23 is important for the proliferation of memory type Th1 cells. Recent studies revealed that IL-27 also has an anti-inflammatory property. In some protozoan infection, various proinflammatory cytokines were over produced causing lethal inflammatory responses in IL-27 receptor-deficient mice. The anti-inflammatory effect of IL-27 depends, at least partly, on inhibition of the development of Th17 cells, a newly identified Th population that is induced by IL-23 and is characterized by the production of the inflammatogenic cytokine, IL-17. IL-27 thus has a double identity as an initiator and as an attenuator of immune responses and inflammation. With the discoveries of the new IL-12-related cytokines and Th17 cells, Th development is facing a new paradigm.

Copyright ( 92007 Hiroki Yoshida et al. This is an open access article distributed under the Creative Commons Attribution License, which permits unrestricted use, distribution, and reproduction in any medium, provided the original work is properly cited.

\section{INTRODUCTION}

Immune responses against pathogens determine the course of infection as well as the pathogenesis of diseases caused by the pathogens. During the responses, immune cells, such as dendritic cells, macrophages, and $\mathrm{T}$ and $\mathrm{B}$ lymphocytes, are orchestrated by various cytokines produced by the immune cells themselves. For instance, during infections with some protozoa, such as Leishmania major or Trypanosoma cruzi, the importance of IFN- $\gamma$ has been proven not only experimentally but also clinically $[1,2]$. IFN- $\gamma$ is produced mainly by helper $\mathrm{T}$ cell $(\mathrm{Th}) 1$-differentiated $\mathrm{CD} 4^{+} \mathrm{T}$ cells, a population induced by IL-12, although other types of cells, such as NK/NKT cells and $\mathrm{CD}^{+} \mathrm{T}$ cells are also known to produce IFN $-\gamma$. While being critically important for the defense against pathogens, cytokines are sometimes notorious as causative agents for the development of immunopathology and inflammation, which may result in organ/tissue damage. TNF- $\alpha$, a cytokine produced by Th1-type $\mathrm{CD} 4^{+} \mathrm{T}$ cells and activated macrophages for defense against intracellular pathogens, may induce cell apoptosis or necrosis depending on situation. Therefore, it is essential that one should mount proper immune responses against pathogens, making sure the response is not too weak to eliminate pathogens or too strong to damage the host. Recently, two new cytokines,
IL-23 and IL-27 have been identified as members of the IL12 cytokine family. With IL-12, a cytokine known as the most potent Th1-inducing cytokine, the IL-12 cytokine family has been shown to be involved in various diseases such as infection, autoimmune diseases, and inflammations. This review will focus on the complicated roles of IL-27, as well as those of related cytokines, and their potential importance during some protozoan infections.

\section{Th1 DIFFERENTIATION AND IL-12 CYTOKINE FAMILY}

When stimulated through $\mathrm{T}$-cell receptors, $\mathrm{CD} 4^{+} \mathrm{T}$ cells proliferate and differentiate into either Th1 or Th2 cells, two functionally distinct subsets that produce characteristic cytokines, respectively [3]. Th1 cytokines, especially IFN- $\gamma$, are critical for the macrophage activation and nitric oxide production required for eliminating intracellular pathogens such as L. major [4]. In contrast, Th2 cytokines such as IL4, IL-5, and IL-13 are important for inducing humoral immunity required to expel helminth from the digestive canal [5]. Th1 and Th2 cells develop from the same Th precursor (Thp or Th0) cells, but which subset differentiates in a given situation is driven by factors, particularly cytokines, in the surrounding microenvironment. IL-12 promotes IFN- $\gamma$ 


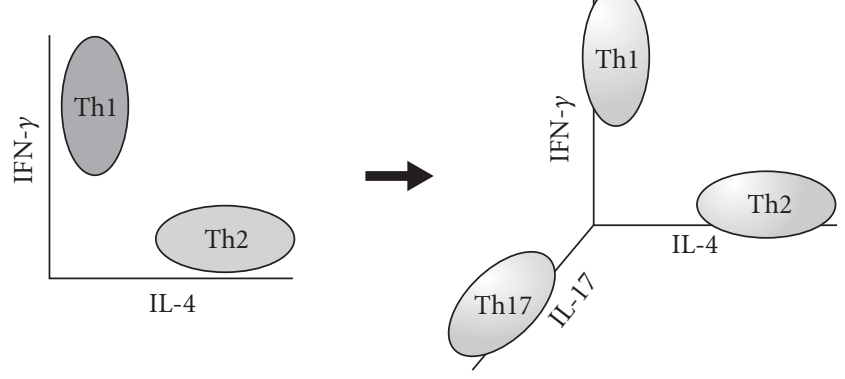

Figure 1: Th1, Th2, and Th17 differentiation. (Left) A traditional Th1 and Th2 differentiation model. Th1 population producing IFN- $\gamma$ versus Th2 population producing IL-4 differentiate in a mutually exclusive manner. (Right) A new Th differentiation model. Additional population producing IL-17 (but producing neither IFN- $\gamma$ nor IL-4) also differentiates from the same precursor cells.

production and Th1 development, whereas IL-4 binding to the IL-4 receptor promotes IL-4 production and Th2 development [6]. Developments of Th1 and Th2 are mutually exclusive and differentiation of one suppresses that of the other by various mechanisms. In addition to these two subsets, recent lines of evidence have shown that there is another Th

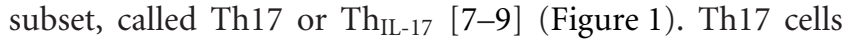
produce IL-17 for induction of various inflammatory responses and for defense against some pathogens $[10,11]$. The differentiation of Th17 cells requires IL- 6 plus TGF- $\beta$ for commitment and IL-23 for development, while other cytokines such as IL- 1 and TNF- $\alpha$ also support the development of Th17 [12-14].

IL-12 was originally identified as a potent inducer of IFN$\gamma$ production by $\mathrm{T}, \mathrm{NK}$, and other types of lymphocytes and was shown later to be a potent inducer of Th1 differentiation of $\mathrm{CD}^{+} \mathrm{T}$ cells [15]. Until recently, IL-12 has been the only known heterodimeric cytokine, composed of two subunits, p35 and p40. The p35 subunit is homologous to IL- 6 and G-CSF with a four- $\alpha$-helix bundle structure, while the $\mathrm{p} 40$ subunit is homologous to the extracellular portion of IL-6R $\alpha$ and related cytokine receptors. Thus, it was proposed that IL-12 evolved from a cytokine of the IL- 6 family, which is covalently bound to the extracellular portion of its primordial $\alpha$ chain receptor [15]. Recently, IL-23 and IL-27 were identified as heterodimeric cytokines functionally and structurally related to IL-12 $[16,17]$ (see $[18,19]$ for review). Now along with two other cytokines, CLC/soluble CNTFR and CLC/CLF-1, IL-12, IL-23, and IL-27 compose a family of heterodimeric cytokines $[18,20]$. IL-23, a heterodimeric cytokine composed of the IL-12p40 subunit and the IL-12p35related molecule p19, preferentially acts on memory Th1 $\mathrm{CD}^{+} \mathrm{T}$ cells for their proliferation [17], although IL-23 has recently been shown to promote Th17 differentiation. IL-27, another heterodimeric cytokine composed of the IL-12p40related protein EBI-3 [21] plus the IL-12p35-related protein $\mathrm{p} 28$, acts on naïve $\mathrm{CD} 4^{+} \mathrm{T}$ cells to induce the expression of the IL-12R $\beta 2$ gene and make the cells responsive to

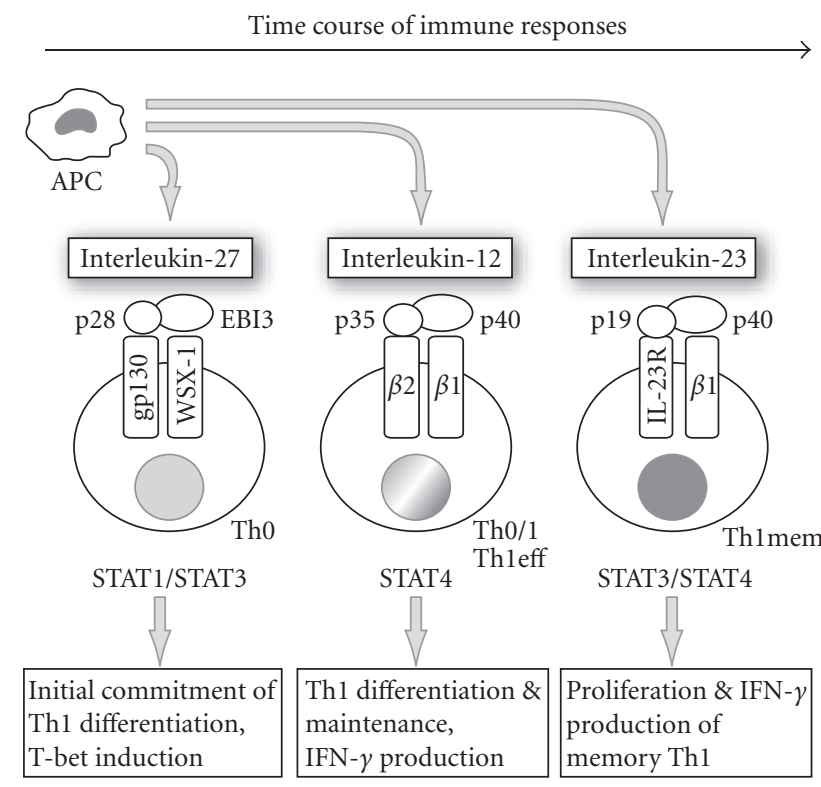

FIgure 2: Differential roles and differential requirement of IL-12 family members during the time course of Th1 development (APC, antigen presenting cells; Th1eff, effector Th1 cells; Th1mem, memory Th1 cells).

IL-12. While IL-12 is the most potent inducer of Th1 differentiation and IFN- $\gamma$ production acting on effector Th 1 cells, chronologically differential roles and differential usage of IL12, IL-23, and IL-27 have been proposed. First, IL-27 commits naïve $\mathrm{CD} 4^{+} \mathrm{T}$ cells to differentiate into Th1 cells by inducing IL-12R $\beta 2$, then IL-12 acts on committed effector Th1 cells for IFN- $\gamma$ production, followed by IL-23 mediating the proliferation of memory Th1 cells [17] (Figure 2). While the Th1 immune response is pivotal for the host defense against pathogens including some bacteria and parasites such as Listeria monocytogenes, Mycobacterium tuberculosis, and L. major (reviewed by Romani et al. in [22]), as well as against tumors [23], excess of Th1 responses may cause some autoimmune diseases including rheumatoid arthritis and multiple sclerosis $[24,25]$. It is of note that recent lines of evidence have shown that some of these "Th1-mediated" autoimmune diseases are actually mediated by IL-23-driven Th17 cell populations but not by IL-12-driven Th1 cell populations, as has been shown for experimental autoimmune encephalomyelitis, an experimental model for multiple sclerosis $[7,8]$ (see also [26, 27] for review). Nonetheless, proper initiation, reinforcement, and maintenance of the Th1 response seems to be ensured, and at the same time tightly regulated by related, but distinct, cytokines [28].

\section{IL-27 AND ITS RECEPTOR, WSX-1, FOR Th1 DIFFERENTIATION}

Sprecher et al. cloned an orphan cytokine receptor and named it WSX-1 (what is now called IL-27R $\alpha$ chain; also known as TCCR) after the WSXWS motif, a characteristic feature of cytokine receptors, in its extracytoplasmic portion 
TABLE 1: Responses of IL-27/IL-27R-deficient mice to parasitic infection.

\begin{tabular}{|c|c|c|c|c|}
\hline Mouse genotype & Pathogen & Helper T cell response & Outcome & Reference \\
\hline$W S X-1^{-/-}$ & Leishmania major & Initial Th1 impaired & $\begin{array}{l}\text { Susceptibility to infection, } \\
\text { normal Th1 at later phase }\end{array}$ & {$[33]$} \\
\hline$W S X-1^{-/-}$ & Trypanosoma cruzi & $\begin{array}{l}\text { Th1, Th2, and } \\
\text { Th17 enhanced }\end{array}$ & $\begin{array}{l}\text { Increased hepatic immunopathology } \\
\text { due to cytokine production }\end{array}$ & {$[45]$} \\
\hline$W S X-1^{-/-}$ & Toxoplasma gondii (acute) & $\begin{array}{l}\text { IFN }-\gamma \text { high } \\
\text { Proliferation high }\end{array}$ & Increased hepatic immunopathology & {$[46]$} \\
\hline$W S X-1^{-/-(a)}$ & Leishmania donovani & Th1 enhanced & Increased hepatic immunopathology & {$[47]$} \\
\hline$W S X-1^{-\prime-}$ & Toxoplasma gondii (chronic) & Th17 enhanced & Exacerbated encephalitis & {$[63]$} \\
\hline$E B I-3^{-/-}$ & Leishmania major & Initial Th1 impaired & $\begin{array}{l}\text { Susceptibility to infection, } \\
\text { enhanced Th1 at later phase }\end{array}$ & {$[34]$} \\
\hline$W S X-1^{-/-}$ & Trichuris muris & Th2 enhanced & Enhanced clearance & {$[35,36]$} \\
\hline
\end{tabular}

(a) TCCR (another name for WSX-1)-deficient mice generated by Chen et al. [32].

[29]. WSX-1 binds to the gp130 (of IL-6R) to conform to a fully functional IL-27 receptor complex, downstream of which, STAT1 and STAT3 are activated by ligand binding $[30,31]$. Although the function of WSX-1 was not clear in the original cloning paper, two groups including ours independently generated strains of mice with WSX-1 (or TCCR) gene disruption and demonstrated that WSX-1 is critical for induction of Th1 responses and IFN- $\gamma$ production. Chen et al. [32] demonstrated that WSX-1 $1^{-/-}$mice showed impaired IFN- $\gamma$ production and remarkable susceptibility to L. monocytogenes. In the report by Yoshida et al. [33], an impairment of Th1 development and IFN- $\gamma$ production was also demonstrated in WSX-1-/- mice infected with L. major. Interestingly, impaired production of IFN- $\gamma$ as only observed at early phases of $L$. major infection, and the IFN- $\gamma$ production in WSX-1 $1^{-/-}$mice was restored to the wild-type level at later phases of infection. In accordance with this "in vivo" observation, $\mathrm{T}$ cells from $W S X-1^{-/-}$mice produced much less IFN- $\gamma$ than wild-type cells during primary stimulation in the presence of IL-12 for Th1 differentiation, while fully differentiated $W S X-1^{-1-}$ Th1 cells produced a comparable level of IFN- $\gamma$ upon secondary stimulation. These data, both "in vivo" and "in vitro," indicated that WSX-1 is required for the initial mounting of the Th1 response by naïve $\mathrm{CD}^{+} \mathrm{T}$ cells, but its role is later mitigated presumably by the IL-12 system in fully activated and differentiated Th1 cells. The importance of WSX-1 in Th1 differentiation was further substantiated by the discovery of IL-27, a ligand for WSX-1, as another Th1-inducing composite cytokine [16]. Early expression of p28, a component of IL-27, prior to that of IL-12 components, by activated dendritic cells also supported the idea that IL-27 was involved in the early phase of Th1 differentiation [16]. A report on the role of EBI-3, a subunit of IL-27, in which EBI-3-deficient mice showed susceptibility to L. major infection with impaired Th1 response also supported the importance of IL-27/WSX-1 in Th1 differentiation [34]. (See Table 1 for comparison.)
While resistance against $L$. major exclusively depends on proper Th1 responses, expulsion of Trichuris muris, a gastrointestinal nematode from digestive canals largely depends on Th2 responses. In our recent T. muris infection experiments $[35,36], W S X-1^{-1-}$ mice successfully expelled the worm and failed to harbor chronic infection in contrast to wild-type mice. WSX-1-/- lymphocytes produced significantly less IFN- $\gamma$ and much more IL- 4 and IL-13 than wildtype cells in response to the worm antigen, reiterating that WSX-1 is important for the initial mounting of proper Th1 responses during infection. Another interpretation of the results, however, is also possible for the impairment of Th1 responses against L. major and T. muris infection. (See below in the following section.)

The molecular basis for the Th1-initiating property of IL-27/WSX-1 was then elucidated [37]. STAT1 was shown to bind to the cytoplasmic portion of WSX-1 in a tyrosine phosphorylation-dependent manner and following STAT1 activation by IL-27 stimulation, T-bet was activated to promote Th1 differentiation. The binding of STAT1 to WSX-1 is reasonable, since WSX-1 has pYEKHF motif at the conserved tyrosine residue, which shares amino acid similarities to the STAT1 docking site of the IFN $-\gamma$ R, pYDKPH $[38,39]$. STAT1 activation per se by IL-27 stimulation has no direct effect on IFN- $\gamma$ production but STAT1-mediated T-bet activation followed by IL-12R $\beta 2$ expression was one of the critical events for Th1 differentiation. Other mechanisms, such as MHC class I augmentation, ICAM-1 expression, and suppression of the expression of GATA-3, a transcription factor pivotal for Th2 differentiation, were also involved for IL-27mediated Th1 differentiation [40-42]. It is now clear that the molecular basis of IL-27/WSX-1-mediated Th1 initiation is the induction of T-bet, which is reminiscent of the finding that the IFN- $\gamma$ stimulation of cells induces T-bet in a STAT-1dependent fashion $[43,44]$. Interestingly, even in the absence of WSX-1, T-bet was induced at later time points after T cell stimulation (our unpublished observation), presumably 
due to the small amount of IFN- $\gamma$ produced or a STAT1independent mechanism yet to be determined [40]. This delayed induction of T-bet may explain the restoration of IFN- $\gamma$ production and IL-12 responsiveness of WSX-1-/- T cells at later time points [45].

\section{SUPPRESSION OF INFLAMMATORY RESPONSES BY IL-27}

In sharp contrast to the finding that IL-27 is important for Th1 promotion, recent reports also demonstrated that IL-27 plays a regulatory role in immune responses. WSX$1^{-1-}$ mice, when infected with T. cruzi or Toxoplasma gondii, showed remarkable sensitivity to the infection $[45,46]$. This high sensitivity to infection was not due to impaired Th1 differentiation or IFN- $\gamma$ production. Unexpectedly, over production of various proinflammatory cytokines including INF- $\gamma$, TNF- $\alpha$, and IL- 6 was observed in infected $W S X-1^{-/-}$ mice, followed by lethal liver necrosis. Rosas et al. also reported severe liver immunopathology in TCCR- (another name for WSX-1) deficient mice infected with Leishmania donovani [47]. Sources of the cytokines were not limited to $\mathrm{T}$ cells, but other types of cells such as NK/NKT cells and macrophages also produced various cytokines. In addition, WSX-1 ${ }^{-/-} \mathrm{CD} 4^{+} \mathrm{T}$ cells were more activated than wild-type cells in terms of cell cycle progression and expression of surface activation makers [46]. Similarly, WSX-1 ${ }^{-/-}$NKT cells produced more of the proinflammatory cytokines, inducing lethal liver damages in Con A-induced liver damage experiment, which is an experimental model of viral or autoimmune hepatitis [48]. Although the development of NKT cells were normal in WSX-1-1- mice, these WSX-1 $1^{-/-}$NKT cells produced more IFN- $\gamma$ and IL-4 than wild-type NKT cells in response to Con A or $\alpha$-galactosyl ceramide stimulation in vitro. When infected with $M$. tuberculosis, WSX-1-1- mice also suffered from liver damages and cachexia due to over production of inflammatory cytokines, such as TNF- $\alpha$ [49]. Interestingly, WSX-1 $1^{-/-}$mice harbored significantly lower bacterial loads over wild-type mice due to higher amounts of TNF- $\alpha$ and IFN- $\gamma$. These results remind us of the fact that immunity against pathogens is a double-edged sword; it kills the pathogens in one way but may hurt the host in another way. Beside the observations described above, IL-27 actually suppressed cytokine production-activated $\mathrm{CD}^{+} \mathrm{T}$ cells [31] in vitro. IL-27 also suppressed cytokine production such as TNF- $\alpha$ and IL-12 by macrophages $[49,50]$. In these reports, IL-27 stimulation induced STAT3 activation and concurrently suppressed cytokine production by LPS-stimulated macrophages. Interestingly, IL-27 stimulation appeared less effective in macrophage suppression than IL-4 or IL-10. Stimulation of macrophages with IL-4, IL-10, or IL-27 resulted in differential gene induction, suggesting distinct suppression mechanisms by respective cytokines [50]. Wirtz et al. also reported the suppressive effect of IL-27 on monocytes and granulocytes reactive oxygen intermediate (ROI) production [51]. Administration of recombinant IL-27 to mice in the septic peritonitis model resulted in higher mortality than untreated mice due to reduced bacterial clearance by the down regulation of granulocyte/monocyte function. Collectively, these data revealed the novel role of IL-27/WSX-1 as an attenuator of proinflammatory cytokine production and cell activation of $\mathrm{T}$ cells as well as macrophages, to suppress excess of inflammation and/or to cease immune responses.

In this regard, a distinct (but not mutually exclusive) hypothesis on the impairment of Th1 responses in the WSX$1^{-/-}$mice should be described. Artis et al. reported an overproduction of IL-4 in L. major-infected WSX-1 ${ }^{-/-}$mice and suggested that the overproduction of Th2 cytokines at early phases of infection reciprocally suppressed the following IFN- $\gamma$ production and Th1 development [52]. Similarly, Artis et al. also reported that upregulation of Th2 responses is independent from Th1 impairment in T. muris-infected $W S X-1^{-/-}$mice, claiming that primary role of IL-27 is the suppression of immune responses (including Th2 responses) but may not be the induction of Th1 differentiation (see [36] and see review by Hunter et al. [53]). Although reconciliation of the two seemingly conflicting ideas awaits further analyses of the role of IL-27 in various settings, a recent report by our group sheds light on this issue [31]. In this report, Yoshimura et al. demonstrated that IL-27 acts on naïve T cells for IFN- $\gamma$ production while the same cytokine suppresses cytokine production by affecting fully activated cells. Therefore, the activation status of the cells may be the key determinant for the effects of IL-27.

The underlying mechanisms for this immune/inflammation suppression by IL-27 are not fully elucidated. It has been reported that IL-27 inhibited IL- 2 production by CD $4^{+}$ $\mathrm{T}$ cells thereby regulating an excess of cell activation $[54,55]$. In WSX-1-1- mice (or cells), however, not only IL-2 production but also the production of various types of cytokines were augmented [45]. Additionally, the source of cytokine production was not limited to $\mathrm{CD}^{+}{ }^{+} \mathrm{T}$ cells, but other types of cells were also affected by WSX-1 deficiency. IL-10 production was unexpectedly augmented similarly by WSX-1 deficiency $[45,46]$ and the so-called regulatory $\mathrm{T}$ cells (Treg) did not appear to be affected by the receptor deficiency [56]. A mechanism that collectively regulates cytokine production and/or cell activation should be taken into consideration.

\section{Th17 AND IL-23 VERSUS IL-27}

IL-23, another IL-12 cytokine family member, has recently been described to induce the differentiation of a new subset of Th cells, namely, Th17 [7, 8, 57]. Th17 cells differentiate from the same precursor cells as Th1 or Th2 cells, during which IL- 6 and TGF- $\beta$ plus IL-23 are required. Th17 cells exclusively produce IL-17, an inflammatogenic cytokine [58], but not IFN- $\gamma$ or IL-4. IL-17 plays a pivotal role in the induction of some inflammatory diseases such as experimental autoimmune encephalomyelitis [7, 59], inflammatory bowel diseases [60], and rheumatoid arthritis [61]. It has also been reported that IL-17 is critically involved in some forms of infection, either by induction of inflammatory cytokines such as TNF- $\alpha$ or by recruiting neutrophils $[10,11]$, although not much is known about the role of IL17 on the defense against parasite infection at this moment 


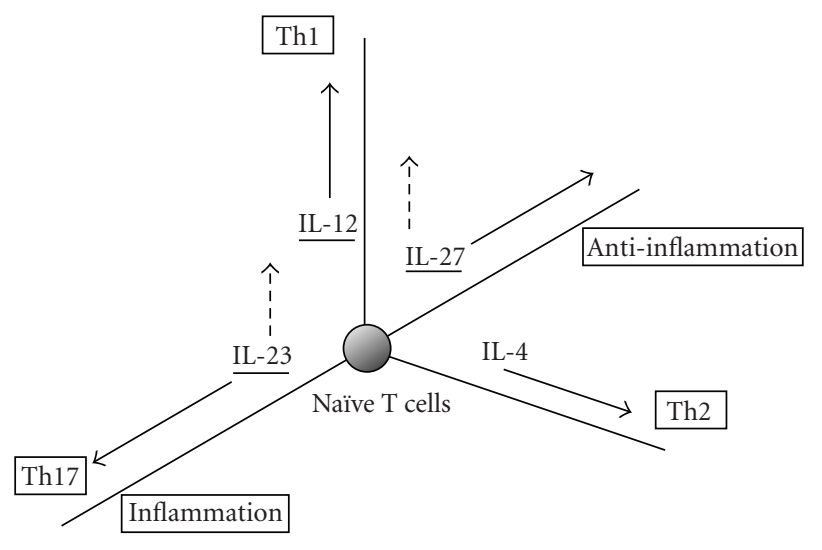

FIgURE 3: Multidimensional regulation of Th cell differentiation by IL-12 family members plus IL-4. Solid arrows show Th1, Th2, and Th17 differentiation axes induced by IL-12, IL-4, and IL-23, respectively, plus anti-inflammatory axis by IL-27. Dashed arrows show roles of IL-27 and IL-23 for Th1 induction. IL-12 cytokine family members are underlined.

[62]. A recent report by Stumhofer et al. revealed an intriguing function of IL-27 in view of its immune suppression [63]. In their report, Stumhofer et al. revealed that WSX-1deficient mice chronically infected with $T$. gondii developed severe neuroinflammation with a prominent IL-17 response. We also reported that IL-27 receptor-deficient mice infected with T. cruzi produced more IL-17 in the sera than wild-type mice [31]. Although the precise role of IL-17 in pathogenesis of encephalomyelitis and infection-induced inflammation has yet to be elucidated, therefore, IL-17 produced in response to pathogens appears at least partially responsible for tissue damages induced by inflammation. In both reports and one by Batten et al. [56], IL-27 suppressed the development of Th17. It is interesting that IL-23, a member of IL12 cytokine family, induces the development of Th17 for the induction of inflammatory responses while IL-27, another member of the family, inhibits the Th17 differentiation to suppress inflammation (Figure 3). Availability of IL-12 family cytokines plus other cytokines, such as IL- 6 and TGF- $\beta$ in the surrounding milieu, may determine the direction of immune responses toward either augmentation or regression. IL-27 thus may be a potential target for treating inflammatory diseases of infection and autoimmune origin mediated by IL-17. The molecular basis for the inhibition of Th17 differentiation is still unclear. While Stumhofer et al. and Batten et al. showed that the IL-27-meidated Th17 inhibition is dependent on STAT1 by taking advantage of STAT1-deficient mice, we demonstrated the requirement of STAT3 for this inhibition by using STAT3-deficient T cells. Although further elucidation of the molecular mechanisms for the IL-27mediated Th17 inhibition is required, it would be reasonable to assume that appropriate balance of STAT1 and STAT3 activation downstream of the receptor determines the function of IL-27 signaling, as implicated by a transgenic mice study [64] or by examination of surface WSX-1 expression on naïve and activated T cells [65].

\section{FUTURE PROSPECT}

Since its discovery, IL-12 has been the only Th1-promoting cytokine for more than 10 years. It has been well recognized that the balance between IL-12-induced Th1 responses versus IL-4-mediated Th2 responses determines the immune responses against pathogens. Discoveries of two other IL-12related cytokines along with the new Th cell population have been challenging and changing the paradigm. As discussed in this review, the IL-12 family members play differential roles in induction and maintenance of Th1 responses during the time course of infection/immune responses. IL-27 is critical in the commitment of Th precursor cells towards Th1 differentiation and IL-27 receptor deficiency resulted in impaired Th1 responses with high susceptibility to L. major infection. While having some overlapping functions, the members of the family also have distinct roles during immune responses. IL-23, one of the new comers to the family, augments inflammation by induction of Th17 cells, while IL-27, the other new comer, attenuates inflammation by suppressing cytokine production. These findings remind us of the intriguing fact that immune responses are elaborately regulated along the time course of infection to fight the dangerous pathogens and to simultaneously avoid hazardous damage to oneself. In this view, the multifaceted role of IL-27 is particularly notable. Although the induction of Th1 differentiation and suppression of cytokine production are seemingly conflicting, these distinct functions are quite reasonable when different target cells (naïve versus activated) and/or different time points (early versus late phase of activation) are taken into consideration. It would be premature to discuss the possibility of using IL-27 for treatment of disease because of the complexity of its role. However, further elucidation of the molecular mechanisms underlying the two distinct functions of IL27 signaling as well as clarification of the situations where the two roles are differentially used will ensure that it will eventually be possible to use IL-27 either to reinforce defense against infectious agents or to treat infection-induced immunopathology and inflammatory diseases.

\section{ACKNOWLEDGMENTS}

The authors would like to thank members of the "Project W" for helpful discussion. The studies described in this review were supported in part by grants from the Ministry of Education, Science, Technology, Sports, and Culture of Japan ( $\mathrm{H}$. Yoshida, S. Hamano, and Y. Yoshiyuki), from the Japan Research Foundation for Clinical Pharmacology (H. Miyazaki), from the Sumitomo Foundation, a grant for Basic Science Research Projects (H. Yoshida), from the Naito Foundation (Y. Yoshida), and from the Takeda Science Foundation (H. Yoshida). S. Wang is a recipient of the Japan Society for the Promotion of Science (JSPS) postdoctoral fellowship for foreign researchers.

\section{REFERENCES}

[1] D. Sacks and N. Noben-Trauth, "The immunology of susceptibility and resistance to Leishmania major in mice," Nature Reviews Immunology, vol. 2, no. 11, pp. 845-858, 2002. 
[2] E. van de Vosse, M. A. Hoeve, and T. H. M. Ottenhoff, "Human genetics of intracellular infectious diseases: molecular and cellular immunity against mycobacteria and salmonellae," Lancet Infectious Diseases, vol. 4, no. 12, pp. 739-749, 2004.

[3] T. R. Mosmann and S. Sad, "The expanding universe of Tcell subsets: Th1, Th2 and more," Immunology Today, vol. 17, no. 3, pp. 138-146, 1996.

[4] S. L. Reiner and R. M. Locksley, "The regulation of immunity to Leishmania major," Annual Review of Immunology, vol. 13, pp. 151-177, 1995.

[5] F. D. Finkelman, T. Shea-Donohue, J. Goldhill, et al., "Cytokine regulation of host defense against parasitic gastrointestinal nematodes: lessons from studies with rodent models," Annual Review of Immunology, vol. 15, pp. 505-533, 1997.

[6] K. M. Murphy, W. Ouyang, J. D. Farrar, et al., "Signaling and transcription in T helper development," Annual Review of Immunology, vol. 18, pp. 451-494, 2000.

[7] C. L. Langrish, Y. Chen, W. M. Blumenschein, et al., "IL23 drives a pathogenic $\mathrm{T}$ cell population that induces autoimmune inflammation," Journal of Experimental Medicine, vol. 201, no. 2, pp. 233-240, 2005.

[8] H. Park, Z. Li, X. O. Yang, et al., "A distinct lineage of CD4 $\mathrm{T}$ cells regulates tissue inflammation by producing interleukin 17," Nature Immunology, vol. 6, no. 11, pp. 1133-1141, 2005.

[9] L. E. Harrington, R. D. Hatton, P. R. Mangan, et al., "Interleukin 17-producing $\mathrm{CD}^{+}$effector $\mathrm{T}$ cells develop via a lineage distinct from the T helper type 1 and 2 lineages," Nature Immunology, vol. 6, no. 11, pp. 1123-1132, 2005.

[10] A. C. Patera, L. Pesnicak, J. Bertin, and J. I. Cohen, "Interleukin 17 modulates the immune response to vaccinia virus infection," Virology, vol. 299, no. 1, pp. 56-63, 2002.

[11] P. Ye, P. B. Garvey, P. Zhang, et al., "Interleukin-17 and lung host defense against Klebsiella pneumoniae infection," American Journal of Respiratory Cell and Molecular Biology, vol. 25, no. 3, pp. 335-340, 2001.

[12] E. Bettelli, Y. Carrier, W. Gao, et al., "Reciprocal developmental pathways for the generation of pathogenic effector $\mathrm{T}_{\mathrm{H}} 17$ and regulatory T cells," Nature, vol. 441, no. 7090, pp. 235-238, 2006.

[13] M. Veldhoen, R. J. Hocking, C. J. Atkins, R. M. Locksley, and B. Stockinger, "TGF $\beta$ in the context of an inflammatory cytokine milieu supports de novo differentiation of IL-17-producing $\mathrm{T}$ cells," Immunity, vol. 24, no. 2, pp. 179-189, 2006.

[14] C. Sutton, C. Brereton, B. Keogh, K. H. G. Mills, and E. C. Lavelle, "A crucial role for interleukin (IL)-1 in the induction of IL-17-producing T cells that mediate autoimmune encephalomyelitis," Journal of Experimental Medicine, vol. 203, no. 7, pp. 1685-1691, 2006.

[15] G. Trinchieri, "Interleukin-12 and the regulation of innate resistance and adaptive immunity," Nature Reviews Immunology, vol. 3, no. 2, pp. 133-146, 2003.

[16] S. Pflanz, J. C. Timans, J. Cheung, et al., "IL-27, a heterodimeric cytokine composed of EBI3 and p28 protein, induces proliferation of naïve CD4 ${ }^{+} \mathrm{T}$ cells," Immunity, vol. 16, no. 6, pp. 779-790, 2002.

[17] B. Oppmann, R. Lesley, B. Blom, et al., "Novel p19 protein engages IL-12p40 to form a cytokine, IL-23, with biological activities similar as well as distinct from IL-12," Immunity, vol. 13, no. 5, pp. 715-725, 2000.

[18] A. V. Villarino, E. Huang, and C. A. Hunter, "Understanding the pro- and anti-inflammatory properties of IL-27," Journal of Immunology, vol. 173, no. 2, pp. 715-720, 2004.
[19] C. A. Hunter, "New IL-12-family members: IL-23 and IL-27, cytokines with divergent functions," Nature Reviews Immunology, vol. 5, no. 7, pp. 521-531, 2005.

[20] G. Trinchieri, S. Pflanz, and R. A. Kastelein, "The IL-12 family of heterodimeric cytokines: new players in the regulation of T cell responses," Immunity, vol. 19, no. 5, pp. 641-644, 2003.

[21] O. Devergne, M. Hummel, H. Koeppen, et al., "A novel interleukin-12 p40-related protein induced by latent EpsteinBarr virus infection in B lymphocytes," Journal of Virology, vol. 70, no. 2, pp. 1143-1153, 1996.

[22] L. Romani, P. Puccetti, and F. Bistoni, "Interleukin-12 in infectious diseases," Clinical Microbiology Reviews, vol. 10, no. 4, pp. 611-636, 1997.

[23] M. P. Colombo and G. Trinchieri, "Interleukin-12 in antitumor immunity and immunotherapy," Cytokine and Growth Factor Reviews, vol. 13, no. 2, pp. 155-168, 2002.

[24] B. Y. Kang and T. S. Kim, "Targeting cytokines of the interleukin-12 family in autoimmunity," Current Medicinal Chemistry, vol. 13, no. 10, pp. 1149-1156, 2006.

[25] B. Skurkovich and S. Skurkovich, "Inhibition of IFN- $\gamma$ as a method of treatment of various autoimmune diseases, including skin diseases," Ernst Schering Research Foundation Workshop, no. 56, pp. 1-27, 2006.

[26] Y. Iwakura and H. Ishigame, "The IL-23/IL-17 axis in inflammation,” Journal of Clinical Investigation, vol. 116, no. 5, pp. 1218-1222, 2006.

[27] B. S. McKenzie, R. A. Kastelein, and D. J. Cua, "Understanding the IL-23-IL-17 immune pathway," Trends in Immunology, vol. 27 , no. 1, pp. 17-23, 2006.

[28] D. S. Robinson and A. O'Garra, "Further checkpoints in Th1 development," Immunity, vol. 16, no. 6, pp. 755-758, 2002.

[29] C. A. Sprecher, F. J. Grant, J. W. Baumgartner, et al., "Cloning and characterization of a novel class I cytokine receptor," Biochemical and Biophysical Research Communications, vol. 246, no. 1, pp. 82-90, 1998.

[30] S. Pflanz, L. Hibbert, J. Mattson, et al., "WSX-1 and glycoprotein 130 constitute a signal-transducing receptor for IL-27," Journal of Immunology, vol. 172, no. 4, pp. 2225-2231, 2004.

[31] T. Yoshimura, A. Takeda, S. Hamano, et al., "Two-sided roles of IL-27: induction of Th1 differentiation on naïve $\mathrm{CD} 4^{+} \mathrm{T}$ cells versus suppression of proinflammatory cytokine production including IL-23-induced IL-17 on activated CD4 ${ }^{+} \mathrm{T}$ cells partially through STAT3-dependent mechanism," Journal of Immunology, vol. 177, no. 8, pp. 5377-5385, 2006.

[32] Q. Chen, N. Ghilardi, H. Wang, et al., "Development of Th1type immune responses requires the type I cytokine receptor TCCR,” Nature, vol. 407, no. 6806, pp. 916-920, 2000.

[33] H. Yoshida, S. Hamano, G. Senaldi, et al., "WSX-1 is required for the initiation of Th1 responses and resistance to L. major infection," Immunity, vol. 15, no. 4, pp. 569-578, 2001.

[34] S. Zahn, S. Wirtz, M. Birkenbach, R. S. Blumberg, M. F. Neurath, and E. von Stebut, "Impaired Th1 responses in mice deficient in Epstein-Barr virus-induced gene 3 and challenged with physiological doses of Leishmania major," European Journal of Immunology, vol. 35, no. 4, pp. 1106-1112, 2005.

[35] A. J. Bancroft, N. E. Humphreys, J. J. Worthington, H. Yoshida, and R. K. Grencis, "WSX-1: a key role in induction of chronic intestinal nematode infection," Journal of Immunology, vol. 172, no. 12, pp. 7635-7641, 2004.

[36] D. Artis, A. Villarino, M. Silverman, et al., "The IL-27 receptor (WSX-1) is an inhibitor of innate and adaptive elements of type 2 immunity," Journal of Immunology, vol. 173, no. 9, pp. 5626-5634, 2004. 
[37] A. Takeda, S. Hamano, A. Yamanaka, et al., "Cutting edge: role of IL-27/WSX-1 signaling for induction of T-bet through activation of STAT1 during initial Th1 commitment," Journal of Immunology, vol. 170, no. 10, pp. 4886-4890, 2003.

[38] M. A. Farrar, J. D. Campbell, and R. D. Schreiber, "Identification of a functionally important sequence in the $\mathrm{C}$ terminus of the interferon- $\gamma$ receptor," Proceedings of the National Academy of Sciences of the United States of America, vol. 89, no. 24, pp. 11706-11710, 1992.

[39] A. C. Greenlund, M. A. Farrar, B. L. Viviano, and R. D. Schreiber, "Ligand-induced IFN $(\gamma)$ receptor tyrosine phosphorylation couples the receptor to its signal transduction system (p91)," EMBO Journal, vol. 13, no. 7, pp. 1591-1600, 1994.

[40] S. Lucas, N. Ghilardi, J. Li, and F. J. de Sauvage, "IL-27 regulates IL-12 responsiveness of naïve $\mathrm{CD}^{+}{ }^{+} \mathrm{T}$ cells through STAT1-dependent and -independent mechanisms," Proceedings of the National Academy of Sciences of the United States of America, vol. 100, no. 25, pp. 15047-15052, 2003.

[41] S. Kamiya, T. Owaki, N. Morishima, F. Fukai, J. Mizuguchi, and T. Yoshimoto, "An indispensable role for STAT1 in IL-27induced T-bet expression but not proliferation of naïve CD4 ${ }^{+}$ T cells," Journal of Immunology, vol. 173, no. 6, pp. 3871-3877, 2004.

[42] T. Owaki, M. Asakawa, N. Morishima, et al., "A role for IL-27 in early regulation of Th1 differentiation," Journal of Immunology, vol. 175, no. 4, pp. 2191-2200, 2005.

[43] M. Afkarian, J. R. Sedy, J. Yang, et al., "T-bet is a STAT1induced regulator for IL-12R expression in naïve $\mathrm{CD}^{+} \mathrm{T}$ cells," Nature Immunology, vol. 3, no. 6, pp. 549-557, 2002.

[44] A. A. Lighvani, D. M. Frucht, D. Jankovic, et al., "T-bet is rapidly induced by interferon- $\gamma$ in lymphoid and myeloid cells," Proceedings of the National Academy of Sciences of the United States of America, vol. 98, no. 26, pp. 15137-15142, 2001.

[45] S. Hamano, K. Himeno, Y. Miyazaki, et al., "WSX-1 is required for resistance to Trypanosoma cruzi infection by regulation of proinflammatory cytokine production," Immunity, vol. 19, no. 5, pp. 657-667, 2003.

[46] A. Villarino, L. Hibbert, L. Lieberman, et al., "The IL-27R (WSX-1) is required to suppress T cell hyperactivity during infection," Immunity, vol. 19, no. 5, pp. 645-655, 2003.

[47] L. E. Rosas, A. A. Satoskar, K. M. Roth, et al., "Interleukin-27R (WSX-1/T-cell cytokine receptor) gene-deficient mice display enhanced resistance to Leishmania donovani infection but develop severe liver immunopathology," American Journal of Pathology, vol. 168, no. 1, pp. 158-169, 2006.

[48] A. Yamanaka, S. Hamano, Y. Miyazaki, et al., "Hyperproduction of proinflammatory cytokines by WSX-1-deficient NKT cells in concanavalin a-induced hepatitis," Journal of Immunology, vol. 172, no. 6, pp. 3590-3596, 2004.

[49] C. Hölscher, A. Hölscher, D. Rückerl, et al., "The IL-27 receptor chain WSX-1 differentially regulates antibacterial immunity and survival during experimental tuberculosis," Journal of Immunology, vol. 174, no. 6, pp. 3534-3544, 2005.

[50] D. Rückerl, M. Heßmann, T. Yoshimoto, S. Ehlers, and C. Hölscher, "Alternatively activated macrophages express the IL27 receptor alpha chain WSX-1," Immunobiology, vol. 211, no. 6-8, pp. 427-436, 2006.

[51] S. Wirtz, I. Tubbe, P. R. Galle, et al., "Protection from lethal septic peritonitis by neutralizing the biological function of interleukin 27," Journal of Experimental Medicine, vol. 203, no. 8, pp. 1875-1881, 2006.
[52] D. Artis, L. M. Johnson, K. Joyce, et al., "Cutting edge: early IL-4 production governs the requirement for IL-27-WSX-1 signaling in the development of protective Th1 cytokine responses following Leishmania major Infection," Journal of Immunology, vol. 172, no. 8, pp. 4672-4675, 2004.

[53] C. A. Hunter, A. Villarino, D. Artis, and P. Scott, "The role of IL-27 in the development of T-cell responses during parasitic infections," Immunological Reviews, vol. 202, no. 1, pp. 106114, 2004.

[54] T. Owaki, M. Asakawa, S. Kamiya, et al., "IL-27 suppresses CD28-medicated IL-2 production through suppressor of cytokine signaling 3," Journal of Immunology, vol. 176, no. 5, pp. 2773-2780, 2006.

[55] A. V. Villarino, J. S. Stumhofer, C. J. M. Saris, R. A. Kastelein, F. J. de Sauvage, and C. A. Hunter, "IL-27 limits IL-2 production during Th1 differentiation," Journal of Immunology, vol. 176, no. 1, pp. 237-247, 2006.

[56] M. Batten, J. Li, S. Yi, et al., "Interleukin 27 limits autoimmune encephalomyelitis by suppressing the development of interleukin 17-producing T cells," Nature Immunology, vol. 7, no. 9, pp. 929-936, 2006.

[57] S. Aggarwal, N. Ghilardi, M.-H. Xie, F. J. de Sauvage, and A. L. Gurney, "Interleukin-23 promotes a distinct CD4 T cell activation state characterized by the production of interleukin-17," Journal of Biological Chemistry, vol. 278, no. 3, pp. 1910-1914, 2003.

[58] J. K. Kolls and A. Lindén, "Interleukin-17 family members and inflammation,” Immunity, vol. 21, no. 4, pp. 467-476, 2004.

[59] Y. Komiyama, S. Nakae, T. Matsuki, et al., "IL-17 plays an important role in the development of experimental autoimmune encephalomyelitis," Journal of Immunology, vol. 177, no. 1, pp. 566-573, 2006.

[60] D. Yen, J. Cheung, H. Scheerens, et al., "IL-23 is essential for $\mathrm{T}$ cell-mediated colitis and promotes inflammation via IL-17 and IL-6," Journal of Clinical Investigation, vol. 116, no. 5, pp. 1310-1316, 2006.

[61] K. Sato, A. Suematsu, K. Okamoto, et al., “Th17 functions as an osteoclastogenic helper T cell subset that links T cell activation and bone destruction," Journal of Experimental Medicine, vol. 203, no. 12, pp. 2673-2682, 2006.

[62] M. N. Kelly, J. K. Kolls, K. Happel, et al., "Interteukin17/interleukin-17 receptor-mediated signaling is important for generation of an optimal polymorphonuclear response against Toxoplasma gondii infection," Infection and Immunity, vol. 73, no. 1, pp. 617-621, 2005.

[63] J. S. Stumhofer, A. Laurence, E. H. Wilson, et al., "Interleukin 27 negatively regulates the development of interleukin 17producing $\mathrm{T}$ helper cells during chronic inflammation of the central nervous system," Nature Immunology, vol. 7, no. 9, pp. 937-945, 2006.

[64] A. Takeda, S. Hamano, H. Shiraishi, et al., "WSX-1 overexpression in $\mathrm{CD}^{+} \mathrm{T}$ cells leads to hyperproliferation and cytokine hyperproduction in response to TCR stimulation," International Immunology, vol. 17, no. 7, pp. 889-897, 2005.

[65] A. V. Villarino, J. Larkin III, C. J. M. Saris, et al., "Positive and negative regulation of the IL-27 receptor during lymphoid cell activation," Journal of Immunology, vol. 174, no. 12, pp. 76847691, 2005. 


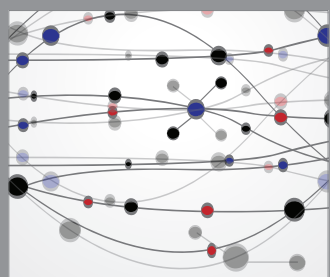

The Scientific World Journal
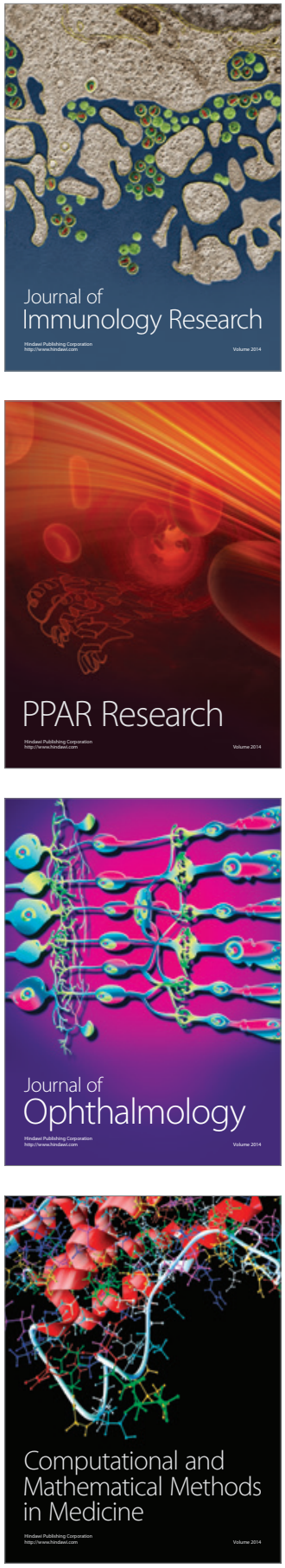

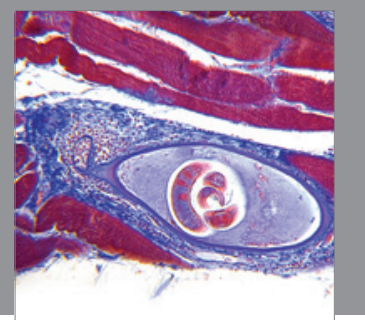

Gastroenterology

Research and Practice
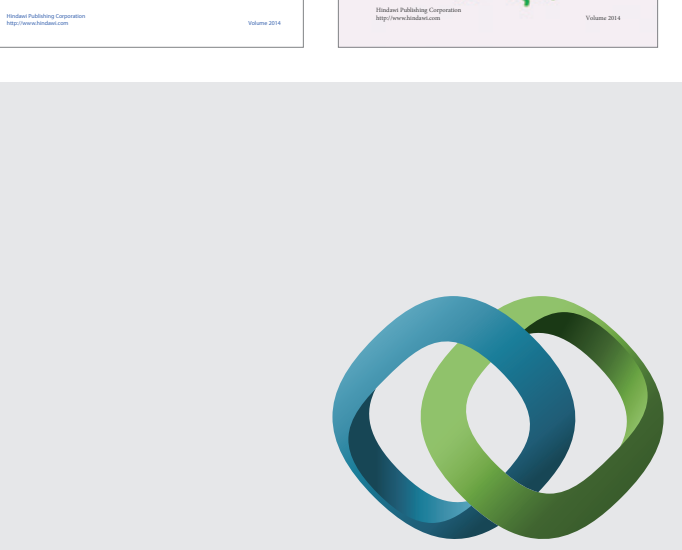

\section{Hindawi}

Submit your manuscripts at

http://www.hindawi.com
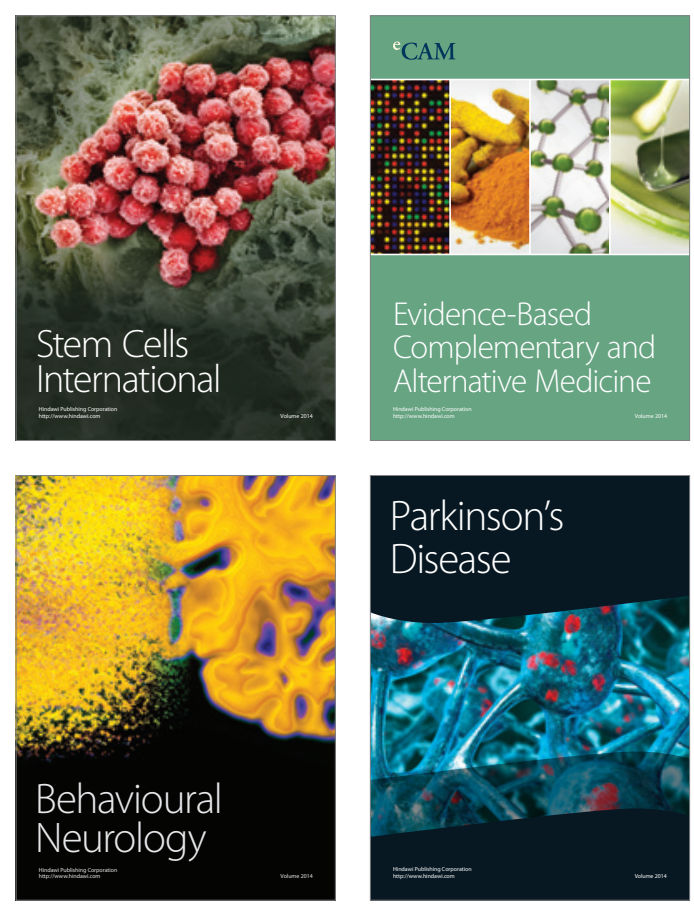

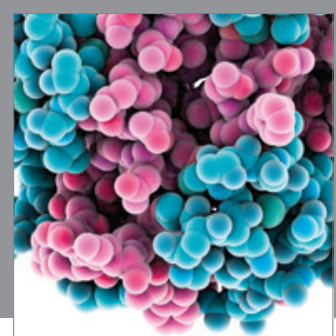

Journal of
Diabetes Research

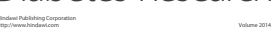

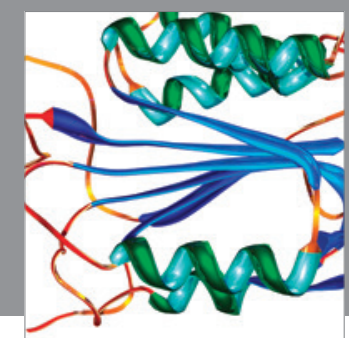

Disease Markers
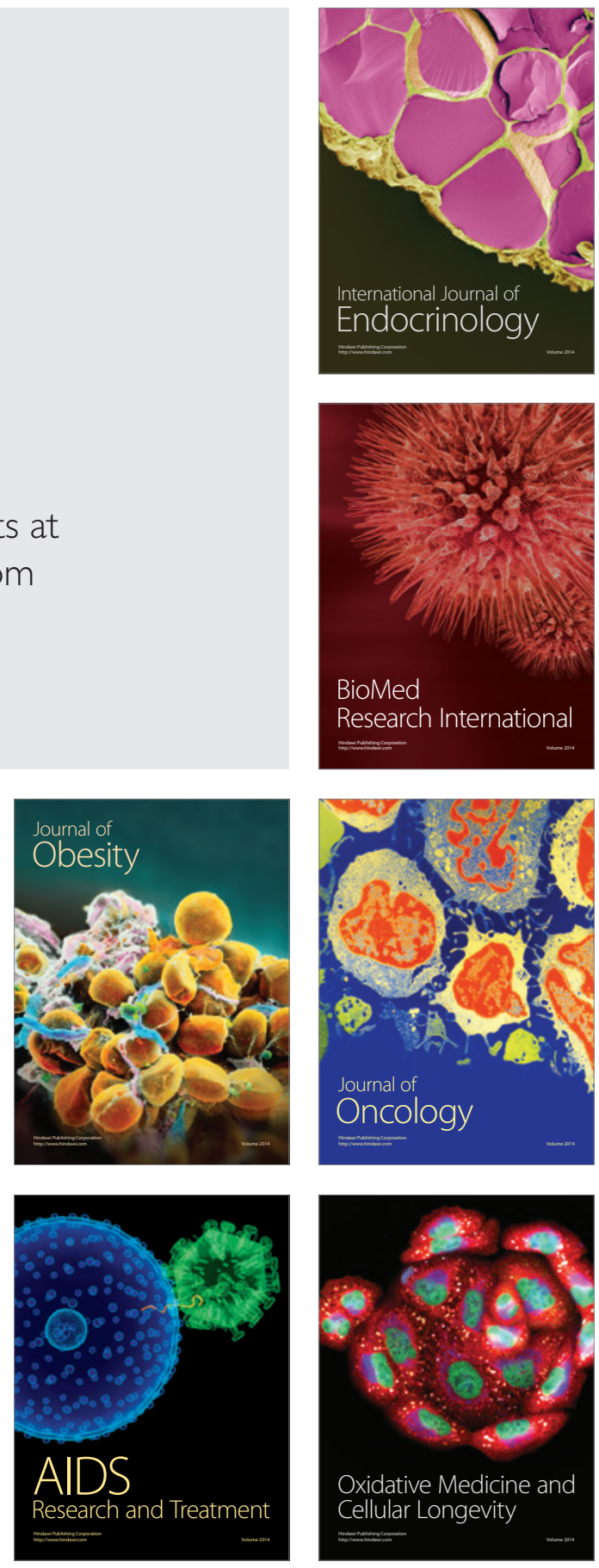